\title{
SARS-CoV-2 PCR and antibody positivity among school staff at the beginning and end of the first school term
}

Moza Alishaq ${ }^{1}$, Andrew Jeremijenko ${ }^{1}$, Hanaa Nafady-Hego ${ }^{2}$, Jameela Ali Al Ajmi', Mohamed Elgendy ${ }^{3}$, Anil George Thomas ${ }^{1}$, Peter V. Coyle ${ }^{1}$, Hamed Elgendy ${ }^{1,4,5}$, Abdul-Badi Abou-Samra ${ }^{1,4}$ and Adeel A. Butt ${ }^{1,4,5,6^{*}}$

\begin{abstract}
Background: There is controversy regarding the role of in-person attendance in schools and transmission of the SARS-CoV-2 pandemic. Several studies have demonstrated no increase in transmission, while some have reported large outbreaks with in-person attendance. We determined the incidence and risk factors for SARS-CoV-2 infection among school staff after one school term.

Methods: Nasopharyngeal swabs (NPS) for SARS-CoV-2 RT-PCR and blood for SARS-CoV-2 antibody testing were obtained from staff at a large international school in Qatar at the beginning of the 2020-2021 school year and repeated at the end of the first term.

Results: A total of 376 staff provided samples for testing. At the beginning of the 2020-2021 school year, the PCR positivity for SARS-CoV-2 was 13\%, while seropositivity was 30.1\%. A majority of those who tested positive either by PCR or serologically, were non-teaching staff. At the end of the first school term four months later, only $3.5 \%$ of the initially antibody-negative staff had seroconverted. In multivariable logistic regression analysis, male gender (OR $11.48,95 \% \mathrm{Cl}$ 4.77-27.64), non-teaching job category (OR 3.09, 95\%Cl 1.10-8.64), contact with a confirmed case (OR $20.81,95 \% \mathrm{Cl} 2.90-149.18)$, and presence of symptoms in the preceding 2 weeks $[1-2$ symptoms OR $4.82,95 \% \mathrm{Cl}$ 1.79-12.94); $\geq 3$ symptoms OR 42.30,95\%Cl 3.76-476.43) independently predicted SARS-CoV-2 infection in school staff before school starting.
\end{abstract}

Conclusion: Male gender, non-teaching job, presence of symptoms, and exposure to a confirmed case were associated with higher risk of infection. These data can help policymakers in determining the optimal strategy for school reopening.

Keywords: COVID-19, SARS-CoV-2, Qatar, Schools

\footnotetext{
* Correspondence: aabutt@hamad.qa

${ }^{1}$ Hamad Medical Corporation, PO Box 3050, Doha, Qatar

${ }^{4}$ Department of Medicine and Department of Population Health Sciences, Weill Cornell Medical College, New York, NY, USA

Full list of author information is available at the end of the article
}

(c) The Author(s). 2021 Open Access This article is licensed under a Creative Commons Attribution 4.0 International License, which permits use, sharing, adaptation, distribution and reproduction in any medium or format, as long as you give appropriate credit to the original author(s) and the source, provide a link to the Creative Commons licence, and indicate if changes were made. The images or other third party material in this article are included in the article's Creative Commons licence, unless indicated otherwise in a credit line to the material. If material is not included in the article's Creative Commons licence and your intended use is not permitted by statutory regulation or exceeds the permitted use, you will need to obtain permission directly from the copyright holder. To view a copy of this licence, visit http://creativecommons.org/licenses/by/4.0/ The Creative Commons Public Domain Dedication waiver (http://creativecommons.org/publicdomain/zero/1.0/) applies to the data made available in this article, unless otherwise stated in a credit line to the data. 


\section{Background}

There is significant controversy regarding the timing of reopening schools with full in-person attendance in the Severe Acute Respiratory Syndrome Coronavirus 2 (SARS-CoV-2) pandemic era. Proponents of early opening with full in-person attendance cite the benefits of human interaction upon the psychological and academic growth of children and the enormous physical, psychological, and financial burden placed on the families as reasons to allow immediate opening with full in-person attendance $[1,2]$. Opponents cite the ongoing pandemic with increasing number of cases, hospitalizations and mortality in infected persons and the possible enhanced role of children in propagation of the pandemic as reasons to delay in-person attendance indefinitely [3, 4]. Understanding the transmission dynamics in schools can help policy makers make informed decisions. Several studies from the United States and Europe have shown no increase in transmission of SARS-CoV-2 infection associated with in-person attendance or school opening $[5,6]$. Conversely, rare large outbreaks with apparent transmission in schools have also been reported [7]. While overall evidence suggests little transmission within schools, controversy still exists regarding the role of schools and in-person attendance with spread of infection. Seroprevalence studies over time have suggested low levels on within-school transmission, with majority of the infections acquired outside the school settings [8]. Within the schools, in-person sporting activities have been associated with a higher risk of transmission [9]. Due to such conflicting evidence, specific recommendations regarding the timing of school opening, and the need for distance or blended learning as opposed to in-person learning are lacking. We undertook this study to define the baseline prevalence of SARS-CoV-2 infection and incidence of infection after one full term of school among the staff of an international school in Qatar.

\section{Methods}

\section{Study population and participants}

As a part of the national testing and screening drive, staff at multiple schools in Qatar provided a nasopharyngeal swab (NPS) to test for the SARS-CoV-2 by realtime reverse transcription polymerase chain reaction (RT-PCR). The 2020-2021 school year in Qatar started on August 25, 2020 with the term ending in the middle of December 2020. A series of measures were implemented in all schools (including the one chosen for the current study) to reduce the likelihood of infection transmission. These included a requirement for all staff to have a negative NPS for SARS-CoV-2 by PCR at the beginning of the school year, hybrid learning for student with maximum $30 \%$ attendance on any given day on a rotational basis, and strict mask use and physical distancing policies for all staff, students and attendants dropping off or picking up students. Based on convenient access, large number of staff, and widespread willingness to participate in the national screening program, we chose one school for analysis. During the study period, the school instituted reduced capacity $(<30 \%$ at any given time), temperature screening of all attendees, display of hand hygiene posters and extensive distribution of hand sanitizers.

\section{Data collection}

As a part of the national surveillance campaign, baseline nasopharyngeal swab for SARS-CoV-2 PCR and blood for SARS-CoV-2 antibody testing at the beginning of the 2020-2021 school year were obtained on all available staff. Repeat testing at the end of the first term was offered to all staff as a part of the ongoing follow-up. All testing was performed at a single national reference laboratory using validated commercial assays as described in our previous studies and detailed below [10, 11]. A brief structured interview was administered to all participants to determine presence of symptoms, accommodation type, exposure to any confirmed cases, and presence of comorbidities. The data collected for above purposes was subsequently secondarily analyzed for the current study purposes.

\section{Laboratory methods}

Roche Elecsys ${ }^{\circledR}$ Anti-SARS-CoV-2 (99.5\% sensitivity, 99.8\% specificity, an electrochemiluminescence immunoassay, was used for antibody detection in the serological samples. Result interpretation followed manufacturer instructions: reactive for optical density (a proxy for antibody titer) cutoff index $\geq 1.0$ and non-reactive for cutoff index $<1.0[12,13]$.

Nasopharyngeal and/or oropharyngeal swabs were collected for RT-PCR testing and placed in Universal Transport Medium (UTM). Aliquots of UTM were: extracted on a QIAsymphony platform (QIAGEN, USA) and tested with real-time reverse-transcription PCR (RT-qPCR) using TaqPath ${ }^{\text {тм }}$ COVID-19 Combo Kits (Thermo Fisher Scientific, USA) on an ABI 7500 FAST (Thermo Fisher, USA); tested directly on the Cepheid GeneXpert system using the Xpert Xpress SARS-CoV-2 (Cepheid, USA); or loaded directly into a Roche cobas ${ }^{\circ}$ 6800 system and assayed with a $\operatorname{cobas}^{\oplus}$ SARS-CoV-2 Test (Roche, Switzerland). The first assay targets the viral $\mathrm{S}, \mathrm{N}$, and ORF1ab gene regions. The second targets the viral $\mathrm{N}$ and E-gene regions, and the third targets the ORF1ab and E-gene regions. All RT-PCR testing was conducted at the Hamad Medical Corporation Central Laboratory following standardized protocols. 


\section{Statistical analysis}

Quantitative data presented as median and IQR (interquartile range) and Mann-Whitney $U$ test was used to compare the study groups. Qualitative data presented in the form of frequency and percentage and Chi-square test was used to compare between the categorical data. Wilcoxon's test was used to compare anti SARS Cov-2 antibody titer before and after school opening. A logistic regression model was used to calculate the odds ratios and $95 \%$ confidence intervals for factors associated with infection (PCR or antibody positivity). Factors that showed a $p$-value of $\leq 0.05$ were included in the multivariable model. Statistical significance was set at $P<0.05$. The data were analyzed using Statistical Package of Social Sciences (IBM-SPSS 21), (SPSS: An IBM Company, version 21.0, IBM Corporation, Armonk, NY, USA).
The study was approved by the Institutional Review Board at Hamad Medical Corporation (approval number MRC-01-20-982). A waiver of informed consent was granted since study procedures were carried out as part of the national pandemic response.

\section{Results}

A total of 376 staff provided a nasopharyngeal swab for PCR testing and a blood sample for serologic testing for SARS-CoV-2 at the beginning of the school year. The median age (IQR [interquartile range]) was 42 years (IQR 36, 49), 43.6\% were males and 56.6\% were teaching staff (Table 1). At the beginning of the school year, only $3.8 \%$ gave a history of exposure to a person with confirmed SARS-CoV-2 infection. Overall, $54.8 \%$ lived in a single family housing unit, $44.1 \%$ in shared

Table 1 Baseline characteristics of the teaching and non-teaching school staff

\begin{tabular}{|c|c|c|c|c|}
\hline & $\begin{array}{l}\text { Total } \\
N=376\end{array}$ & $\begin{array}{l}\text { Teaching staff } \\
N=213\end{array}$ & $\begin{array}{l}\text { Non-teaching staff } \\
N=163\end{array}$ & $p$-value \\
\hline Median age (IQR), years & $42(36,49)$ & $41(36,47)$ & $43(36,51)$ & 0.09 \\
\hline Male sex, N (\%) & $165(43.6)$ & $39(18.3)$ & $126(77.3)$ & $<0.0001$ \\
\hline Nationality, N (\%) & & & & $<0.0001$ \\
\hline Indian & $287(76.3)$ & $206(96.7)$ & $81(49.7)$ & \\
\hline Nepalese & $63(16.8)$ & $1(0.5)$ & $62(38.0)$ & \\
\hline Sri Lankan & $15(4.0)$ & $2(0.9)$ & $13(8.0)$ & \\
\hline Bangladeshi & $4(1.1)$ & $1(0.5)$ & $3(1.8)$ & \\
\hline Filipino & $2(0.5)$ & 0 & $2(1.2)$ & \\
\hline Kenyan & $2(0.5)$ & 0 & $2(1.2)$ & \\
\hline Others & $3(0.8)$ & $3(1.4)$ & 0 & \\
\hline Type of accommodation, N (\%) & & & & $<0.0001$ \\
\hline Single & $4(1.1)$ & $3(1.4)$ & $1(0.6)$ & \\
\hline Shared & $166(44.1)$ & $32(15)$ & $134(82.2)$ & \\
\hline Family & $206(54.8)$ & $178(83.6)$ & $28(17.2)$ & \\
\hline Job category, N (\%) & & & & $<0.0001$ \\
\hline Teachers & $213(56.6)$ & $213(100)$ & N/A & \\
\hline Administrative and support staff & $70(18.6)$ & $\mathrm{N} / \mathrm{A}$ & $70(42.9)$ & \\
\hline Transportation and security staff & $58(15.4)$ & N/A & $58(35.6)$ & \\
\hline Technician/conductor/laboratory workers & $21(5.6)$ & N/A & $21(12.9)$ & \\
\hline Service staff & $14(3.7)$ & N/A & $14(8.6)$ & \\
\hline Median Education years (IQR) & $16(10,16)$ & $16(16,16)$ & $10(9,12)$ & $<0.0001$ \\
\hline PCR positive & $49(13.0 \%)$ & $8(16.3 \%)$ & $41(83.7 \%)$ & $<0.0001$ \\
\hline Median (IQR) Ct Values & $23.8(18.2,30.0)$ & $19.7(17.1,33.2)$ & $23.8(18.3,30.0)$ & \\
\hline Antibody positive & $113(30.1 \%)$ & $19(16.8 \%)$ & $94(83.2 \%)$ & $<0.0001$ \\
\hline Median (IQR) antibody titer & $61.3(18.0,101.0)$ & $60.7(16.6,96.5)$ & $61.5(18.3,101.2)$ & \\
\hline History of contact with confirmed cases & $14(3.8 \%)$ & $5(35.7 \%)$ & $9(64.3 \%)$ & 0.11 \\
\hline Presence of clinical symptoms & $113(30.1 \%)$ & $88(77.9 \%)$ & $25(22.1 \%)$ & 0.03 \\
\hline Presence of Co morbidities & $32(8.5 \%)$ & $17(53.1 \%)$ & 15 (46.9\%) & 0.69 \\
\hline
\end{tabular}


accommodation and $1.1 \%$ lived alone in single-person accommodations.

At the beginning of the school year, 49 (13.0\%) were PCR-positive; $8(16.3 \%)$ of them were teachers, while 113 (30.1\%) were seropositive for SARS-CoV-2; 19 (16.8\%) were teachers. Nearly one-third (30.1\%) reported having at least one symptom compatible with SARSCoV-2 infection in the 2 weeks preceding the testing. Only $14(3.8 \%)$ reported history of contact with a person with confirmed SARS-CoV-2 infection (Table 1).

At baseline, 113 (30.1\%) were seropositive for SARSCoV-2 antibody. Follow-up serology at the end of the first school term was available for 100 of these staff (median time to re-testing 17.1, IQR 17.1, 17.4 weeks) with 97 (97.0\%) remaining seropositive. Of the 263 staff with a negative serology at baseline, 231 were retested at the end of the first term (median 17.3 weeks, IQR 17.1, 17.4 weeks) and $8(3.5 \%)$ were seropositive (Fig. 1). Of the seroconverted $7(87.5 \%)$ were teachers and 6 of them had PCR positive results. Anti SARS Cov- 2 antibody titer significantly reduced after school opening in nonteaching staff (median antibody before and after school opening: 61.5 (IQR: 18.28, 101.25), and 30 (IQR: 8.4, $70.8)$ respectively; $P<0.0001)$. The change in teaching staff before and after school opening was not significant. (median antibody titer before and after school opening: 60.7 (IQR: 16.6, 96.5), and 47.7 (IQR: 23.6, 106.6) respectively; $p=0.87$ ).

In multivariable logistic regression analysis, male gender (OR 11.48, 95\%CI 4.77-27.64, $p<0.0001$ ), nonteaching profession (OR 3.09, 95\% CI 1.10-8.64, $p=$ 0.03 ) contact with a confirmed case (OR 20.81, 95\% CI $2.90-149.18, p=0.003$ ), and presence of symptoms in the preceding 2 weeks [1-2 symptoms (OR 4.82, 95\% CI 1.79-12.9), (3 or more symptoms (OR 42.30, 95\% CI $3.76-476.43$,) $p=0.002)$ ] independently predicted SARS-

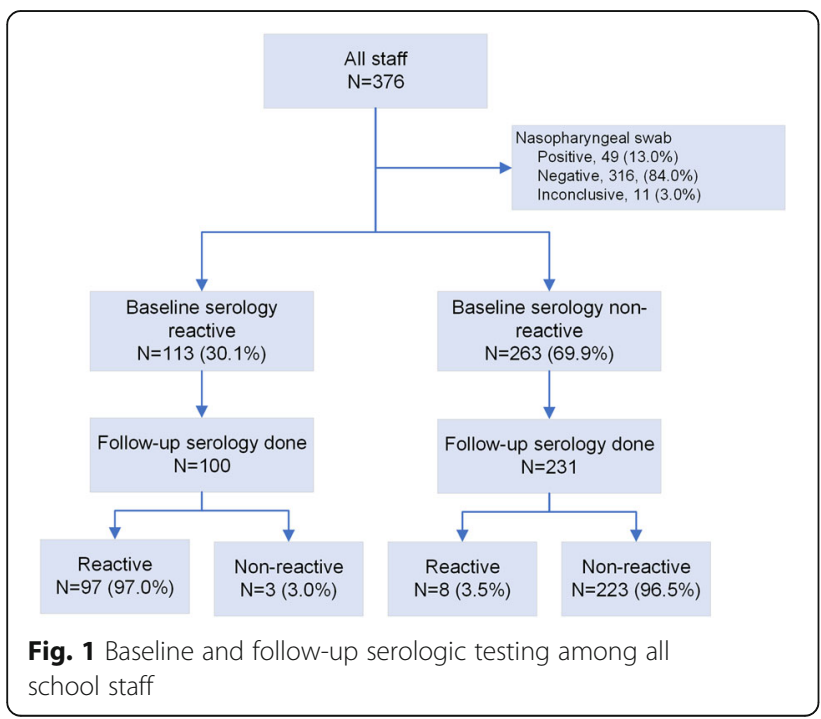

CoV-2 infection (PCR or antibody positive) in school staff before school starting (Table 2).

\section{Discussion}

Our study provides critical insights into the SARS-CoV2 infection dynamics among the staff of a large school which can help inform policymakers make informed decisions on school openings.

At the beginning of the school year, $13 \%$ of the staff were positive by PCR on a NPS sample and therefore likely infectious. Since every staff member was required to get tested before resuming duty, this represents a true infection rate. At that point in time, approximately 5\% of Qatar's population had been diagnosed with SARSCoV-2 infection [10]. However, the national positivity rate reflects only those who were tested and is not a true reflection of infection prevalence in the country. Indeed, in certain population subgroups in Qatar, infection rates in excess of $50 \%$ had been reported [11]. Importantly, the requirement to test every staff member prior to resuming duty removed potentially infectious persons from the school environment thereby reducing the risk of transmission to students and coworkers.

At the beginning of the school year, the seroprevalence among the staff was $30 \%$. This implies that a large proportion of persons were not diagnosed at the time of acute infection when their potential to transmit infection is the highest. Antibody testing is not a robust strategy to reduce the transmission of infection since antibody response lags the infectious period by days to weeks. Antibody testing may be helpful in identifying staff with prior infection who may now be immune to reinfection and therefore unlikely to transmit infection. Whether persons with prior natural infection and spontaneous recovery may still harbor the virus and potentially transmit it is not entirely clear. Of the 113 seropositive persons at baseline in our study, 49 (43\%) also had a positive NPS by PCR. One possible explanation is that these persons were recently infected and were in the overlap period between complete viral clearance and early antibody response.

The prevalence of acute infection (PCR positivity) and seropositivity at baseline were lower among teaching staff compared with the non-teaching staff. This is likely due to the majority of teaching staff living in a single family setting while the majority of the non-teaching staff were living in shared accommodations with nonrelated room-mates. In other studies from Qatar, the infection rate among craft and manual workers sharing accommodations has been shown to be much higher than the population living in family accommodations [11, 14]. History of contact with a confirmed infected case, male gender, sharing accommodations, and presence of symptoms were strongly associated with infection before the 
Table 2 Factors associated with SARS-CoV-2 infection at the initial visit in school staff (PCR positive and/or antibody positive; multivariable logistic regression analysis)

\begin{tabular}{|c|c|c|c|}
\hline & Odds ratio (OR) & $95 \% \mathrm{Cl}$ & $p$-value \\
\hline Age/years & 1.008 & $(0.974-1.043)$ & 0.6 \\
\hline Male gender & 11.48 & $(4.771-27.641)$ & $<0.0001$ \\
\hline Education/years & 0.90 & $(0.797-1.025)$ & 0.1 \\
\hline Non-teaching staff (vs. teaching staff) & 3.09 & $(1.102-8.638)$ & 0.03 \\
\hline Shared accommodation & 2.25 & $(.899-5.654)$ & 0.08 \\
\hline History of contact with confirmed cases & 20.81 & (2.904-149.184) & 0.003 \\
\hline \multicolumn{4}{|l|}{ Symptoms in the 2 weeks prior to testing } \\
\hline None & Ref. & & \\
\hline $1-2$ & 4.82 & $(1.792-12.94)$ & 0.002 \\
\hline 3 or more & 42.30 & $(3.756-476.432)$ & 0.002 \\
\hline \multicolumn{4}{|l|}{ Co morbidities } \\
\hline None & Ref. & & \\
\hline $1-2$ & 1.05 & $(0.26-4.213)$ & 0.9 \\
\hline 3 or more & 3.70 & $(0.312-43.78)$ & 0.3 \\
\hline
\end{tabular}

school opening. These can explain the lower prevalence of SARS-CoV-2 infection among teachers, since a majority of the teachers were females, living in family accommodations and the sample timing was 5 months after school closure in Qatar. Male school staff are predominantly in the transportation department (school bus drivers, conductors) and security. They also tend to be overwhelmingly single and live in shared accommodation with non-family members. Hence, their exposure is more than female staff, who are predominantly teachers, who are married and liver with their own family. We previously reported the strong correlation between shared accommodation and viral infection [15]. These results suggests that teachers pose a low risk of infection transmission, and if a decision to reopen schools were to be made, a targeted screening of non-teaching staff may be a useful strategy to reduce transmission. Previously published reports from other countries support our results. In a study from Germany that included 177 primary and 175 secondary school students, 142 staff and 625 household members, prevalence of SARS-CoV-2 infection was $2.7 \%$ among students, $1.4 \%$ among staff, and $2.3 \%$ among household members. Contact with confirmed cases outside the school was associated with infection among study participants [16]. Low attack rates within schools were also reported from a large study from North Carolina, USA, which included over 100,000 staff and students from 13 school districts [9]. An Italian study did not find any increase in infection incidence among students who attended in-person classes compared with those who attended remote learning [8]. On the other hand, breakdown in infection control practices, e.g. not wearing a mask especially by unvaccinated teachers or staff, has been associated with large outbreak among their students [17].

A limitation of our study is that it was conducted at a single school and may not be representative of the entire school staff population in the country, or indeed rest of the world. However, repeat testing on the same population before and after the opening of the school provides an accurate and clear picture of infection dynamics. Another limitation is that we did not assess the infection rates among students. Based on national surveillance data, there was no spike in infection rates among children of school-going age during that period. However, this population is not routinely screened so firm conclusions cannot be drawn.

\section{Conclusion}

Our study provides data that can be used to design a logical testing and screening strategy for school staff, and to devise an evidence-based strategy to reopen in-person learning in a safe manner. Based on our data and prior literature on this subject, teachers are less likely to transmit infection to students if a strict vaccination and masking policy is enforced. Non-teaching staff may pose a higher risk due to their more frequent exposure risk. Targeted screening strategies can be developed to mitigate the risk of infection transmission in schools.

\section{Abbreviations}

COVID-19: Coronavirus disease; IQR: interquartile range; NPS: Nasopharyngeal swabs; OR: Odds ratio; RT-PCR: Real-Time- Polymerase Chain Reaction; SARSCoV-2: Severe acute respiratory syndrome coronavirus 2

\section{Acknowledgements}

The authors are grateful for the leadership and assistance provided by the Ministry of Public Health in Qatar, the System-Wide Incident Command and 
Control Center and the Business Intelligence Unit at Hamad Medical Corporation, and all the dedicated frontline healthcare workers who have selflessly served and provided care and comfort to all patients in Qatar. The views expressed in this article are those of the authors and do not necessarily represent official government views or policy of the State of Qatar or Hamad Medical Corporation

\section{Authorship statement}

Dr. M. Alishaq had complete access to data at all times and accepts the responsibility of the integrity of this article.

\section{Authors' contributions}

All authors have read and approved the manuscript. Concept and study design: MA, AJ, HN-H., JAAA, HE, ABAS, AAB. Drafting of the manuscript: $H N-$ $\mathrm{H}, \mathrm{AAB}$. Data acquisition: HN-H, AGT, ME. Data analysis: HN-H. Data interpretation: HN-H, MA, AJ, AAB. Critical appraisal and review: MA, AJ, HN-H., JAAA, $M E, A G T, H E, P V C, A B A S, A A B$.

\section{Funding}

No funding was obtained for this study.

\section{Availability of data and materials}

The datasets used and/or analysed during the current study available from the corresponding author on reasonable request.

\section{Declarations}

\section{Ethics approval and consent to participate}

All methods were carried out in accordance with relevant guidelines and regulations. The Institutional Review Board at Hamad Medical Corporation approved this study. A waiver of informed consent was granted since testing was done as part of a national testing campaign in response to a national health emergency. (Hamad Medical Corporation institutional Review Board: MRC-01-20-982)

\section{Consent for publication.}

Not Applicable.

\section{Competing interests}

The authors declare that they have no competing interests.

\section{Author details}

${ }^{1}$ Hamad Medical Corporation, PO Box 3050, Doha, Qatar. ${ }^{2}$ Microbiology and Immunology Department, Faculty of Medicine, Assiut University, Assiut, Egypt. ${ }^{3}$ Faculty of Medicine, Universiti Sains of Malaysia, Kota Bharu, Kelantan, Malaysia. ${ }^{4}$ Department of Medicine and Department of Population Health Sciences, Weill Cornell Medical College, New York, NY, USA. ${ }^{5}$ Anesthesia Department, Faculty of Medicine, Assiut University, Assiut, Egypt. ${ }^{6}$ Weill Cornell Medicine - Qatar, Doha, Qatar.

\section{Received: 10 August 2021 Accepted: 28 October 2021}

Published online: 11 November 2021

\section{References}

1. Levinson M, Cevik M, Lipsitch M. Reopening primary schools during the pandemic. N Engl J Med. 2020;383(10):981-5. https://doi.org/10.1056/ NEJMms2024920.

2. Christakis DA, Van Cleve W, Zimmerman FJ. Estimation of US Children's educational attainment and years of life lost associated with primary school closures during the coronavirus disease 2019 pandemic. JAMA Netw Open. 2020;3(11):e2028786. https://doi.org/10.1001/jamanetworkopen.2020.28786.

3. Stringhini S, Wisniak A, Piumatti G, Azman AS, Lauer SA, Baysson $H$, et al. Seroprevalence of anti-SARS-CoV-2 IgG antibodies in Geneva, Switzerland (SEROCoV-POP): a population-based study. Lancet. 2020;396(10247):313-9. https://doi.org/10.1016/50140-6736(20)31304-0.

4. Staguhn ED, Castillo RC, Weston-Farber E. The impact of statewide school closures on COVID-19 infection rates. Am J Infect Control. 2021;49(4):503-5. https://doi.org/10.1016/j.ajic.2021.01.002.

5. Hobbs CV, Martin LM, Kim SS, Kirmse BM, Haynie L, McGraw S, et al. Factors associated with positive SARS-CoV-2 test results in outpatient health facilities and emergency departments among children and adolescents aged <18 years - Mississippi, September-November 2020. MMWR Morb Mortal Wkly Rep. 2020;69(50):1925-9. https://doi.org/10.15585/mmwr. mm6950e3.

6. Zimmerman KO, Akinboyo IC, Brookhart MA, Boutzoukas AE, McGann KA, Smith MJ, et al. Incidence and secondary transmission of SARS-CoV-2 infections in schools. Pediatrics. 2021;147(4):e2020048090. https://doi.org/1 0.1542/peds.2020-048090.

7. Stein-Zamir C, Abramson N, Shoob H, Libal E, Bitan M, Cardash T, et al. A large COVID-19 outbreak in a high school 10 days after schools' reopening, Israel, may 2020. Euro Surveill. 2020;25(29). https://doi.org/10.2807/1560-791 7.ES.2020.25.29.2001352.

8. Barcellini L, Forlanini F, Sangiorgio A, Gambacorta G, Alberti L, Meta A, et al. Does school reopening affect SARS-CoV-2 seroprevalence among schoolage children in Milan? PLoS One. 2021;16(9):e0257046. https://doi.org/10.13 71/journal.pone.0257046.

9. Zimmerman KO, Brookhart MA, Kalu IC, Boutzoukas AE, McGann KA, Smith MJ, et al. Community SARS-CoV-2 surge and within-school transmission. Pediatrics. 2021;148(4):e2021052686. https://doi.org/10.1 542/peds.2021-052686.

10. Coyle PV, Chemaitelly H, Ben Hadj Kacem MA, et al. SARS-CoV-2 seroprevalence in the urban population of Qatar: An analysis of antibody testing on a sample of 112,941 individuals. iscience. 2021:24:102646.

11. Jeremijenko A, Chemaitelly $H$, Ayoub HH, Ayoub HH, Alishaq M, AbouSamra $A B$, et al. Herd immunity against severe acute respiratory syndrome coronavirus 2 infection in 10 communities, Qatar. Emerg Infect Dis. 2021; 27(5):1343-52. https://doi.org/10.3201/eid2705.204365.

12. Muench $P$, Jochum $S$, Wenderoth $V$, Ofenloch-Haehnle B, Hombach $M$, Strobl M, et al. Development and validation of the Elecsys anti-SARS-CoV-2 immunoassay as a highly specific tool for determining past exposure to SARS-CoV-2. J Clin Microbiol. 2020;58(10). https://doi.org/10.1128/JCM.01 694-20.

13. Roche's COVID-19 antibody test receives FDA Emergency Use Authorization and is available in markets accepting the CE mark. 2020. at https://www. roche.com/media/releases/med-cor-2020-05-03.htm. Accessed on September 19, 2021.)

14. Abu-Raddad L, Chemaitelly H, Ayoub HH, al Kanaani Z, al Khal A, al Kuwari E, et al. Characterizing the Qatar advanced-phase SARS-CoV-2 epidemic. Sci Rep. 2021;11(1):6233. https://doi.org/10.1038/s41598-021-85428-7.

15. Alishaq M, Jeremijenko A, Nafady-Hego H, Al Ajmi JA, Elgendy M, Fadel RAA, et al. SARS-CoV-2 infection in mortuary and cemetery workers. Int J Infect Dis. 2021 Mar;9:621-5. https://doi.org/10.1016/j.jijid.2021.03.012.

16. Theuring S, Thielecke M, van Loon W, Hommes F, Hülso C, von der Haar A, et al. SARS-CoV-2 infection and transmission in school settings during the second COVID-19 wave: a cross-sectional study, Berlin, Germany, November 2020. Euro surveillance : bulletin Europeen Sur les maladies transmissibles $=$. European communicable disease bulletin. 2021;26(34). https://doi.org/10.2 807/1560-7917.ES.2021.26.34.2100184.

17. Lam-Hine T, McCurdy SA, Santora $L$, et al. Outbreak Associated with SARSCoV-2 B.1.617.2 (Delta) Variant in an Elementary School - Marin County, California, May-June 2021. MMWR Morb Mortal Wkly Rep. 2021;70(35):12149. https://doi.org/10.15585/mmwr.mm7035e2.

\section{Publisher's Note}

Springer Nature remains neutral with regard to jurisdictional claims in published maps and institutional affiliations.

Ready to submit your research? Choose BMC and benefit from:

- fast, convenient online submission

- thorough peer review by experienced researchers in your field

- rapid publication on acceptance

- support for research data, including large and complex data types

- gold Open Access which fosters wider collaboration and increased citations

- maximum visibility for your research: over $100 \mathrm{M}$ website views per year

At $\mathrm{BMC}$, research is always in progress.

Learn more biomedcentral.com/submissions 